\title{
Homelessness and incarceration among psychiatric patients in Brazil
}

\author{
Pacientes psiquiátricos em situação de rua e encarceramento \\ no Brasil
}

Ana Paula Souto Melo ${ }^{1}$

Eduardo de Paula Lima ${ }^{2}$

Fabiana Cristina Ribeiro de Barros ${ }^{2}$

Lidyane do Valle Camelo ${ }^{2}$

Mark Drew Crosland Guimarães ${ }^{2}$

${ }^{1}$ Faculdade de Medicina, Universidade Federal de São João Del-Rei. Av. Sebastião Gonçalves Coelho 400/209A, Bairro Chanadour. 35501-296 Divinópolis MG Brasil. ana.paula.souto.melo@ gmail.com

${ }^{2}$ Departamento de Medicina Preventiva e Social, Faculdade de Medicina, Universidade Federal de Minas Gerais. Belo Horizonte MG Brasil.

\begin{abstract}
Psychiatric patients are at increased risk of adverse life events, such as being incarcerated and homelessness in their life course. Using data from a cross-sectional multicenter study of 2,475 patients selected from 26 mental health services in Brazil, we examined the association of sociodemographic, clinical, behavioral, and adverse life characteristics with history of homelessness, incarceration or their co-occurrence during lifetime. Odds ratios were obtained by multinomial logistic regression models. The prevalence of homelessness, incarceration and co-occurrence of these two conditions were $8.6 \%, 16.4 \%$, and 9.4\%, respectively. Lower income, living in unstable condition, intellectual disability, and cigarette smoking were associated with homelessness. Being male, lower schooling, sex under effect of alcohol or drugs, and multiple sex partners were associated with incarceration. Psychiatric hospitalizations, substance use, and history of sexually transmitted diseases, and sexual, physical, or verbal violence were associated with co-occurrence of both conditions. Our findings suggest that incarceration and homelessness are very prevalent and correlated in psychiatric patients in Brazil. Many of the associated factors are potentially modifiable, and may act synergistically requiring integrated care.

Key words Homeless persons, Mental disorders, Epidemiology, Prisons
\end{abstract}

Resumo Os pacientes psiquiátricos estão em risco aumentado de eventos adversos da vida, como ser preso e morar na rua. Investigamos a associação de características sociodemográficas, clínicas, comportamentais e eventos adversos de vida com o histórico de morar na rua, encarceramento e a coocorrência dessas duas condições ao longo da vida em um estudo multicêntrico de corte transversal de 2.475 usuários de 26 serviços de saúde mental no Brasil. "Odds ratios" foram obtidos por modelos de regressão logística multinomial. A prevalência de morar na rua, encarceramento e coocorrência dessas condições foi de 8,6\%, 16,4\% e 9,4\%, respectivamente. Menor renda, viver em habitações instáveis, deficiência mental e tabagismo foram associados a morar na rua. Ser do sexo masculino, ter menor escolaridade, histórico de sexo sob efeito de álcool ou drogas e múltiplos parceiros sexuais foram associados ao encarceramento. Internações psiquiátricas, uso de substâncias, histórico de doenças sexualmente transmissíveis e violência sexual, física ou verbal foram associados à coocorrência das duas condições. Encarceramento e morar na rua são eventos muito prevalentes e correlacionados em pacientes psiquiátricos. Muitos dos fatores associados são modificáveis e podem agir sinergicamente exigindo cuidados integrados.

Palavras-chave Pessoas em situação de rua, Transtornos mentais, Epidemiologia, Prisões 


\section{Introduction}

Individuals with mental illness are potentially vulnerable to a higher risk of several health conditions and they often live under disadvantage social contexts with increased risk of adverse life events, including being incarcerated and having episodes of homelessness in their life course ${ }^{1,2}$. Prevalence of homelessness among severe mental illness from a large public mental health system in the USA reached $15 \%$ in a single year ${ }^{3}$.

A national survey in the USA $(\mathrm{N}=6,953)$ reported high prevalence of mental illness, substance abuse, previous arrests, and prior episodes of homelessness among jail inmates ${ }^{4}$. Moreover, various authors indicate that approximately $50 \%$ $80 \%$ among homeless people have a history of mental illness, suffer from substance use disorders, and have histories of previous incarceration ${ }^{5-10}$.

Homelessness poses an increased risk of incarceration and incarceration in turn precipitates homelessness by disrupting social networks and employment opportunities ${ }^{11}$. For example, Saddichha et al. ${ }^{12}$ found an unusually high prevalence of incarceration among the homeless $(65 \%)$ in three cities from Canada, which is higher than the 50\%-55\% prevalence that has been reported in earlier study from similar populations $s^{5}$. Incarceration and homelessness share many factors and this intertwined relationship poses those with history of both conditions at the greatest risk of suffering from mental health issues and substance abuse ${ }^{12}$.

Prison and jail stays as well as homelessness also increase the risks of unsafe sexual, behavior, HIV infection, drug use, and physical and sexual violence $^{11,13}$. Furthermore, high mortality rates are associated with homelessness ${ }^{14}$ and incarceration, as compared to the general population ${ }^{11}$.

Hawthorne et al. ${ }^{7}$, studying incarcerated population among adults who are in the Public Mental Health System in the USA, found that risk factors for incarceration included prior incarcerations, co-occurring substance-related diagnoses, homelessness, schizophrenia, bipolar, or other psychotic disorder diagnoses, male gender, no medicaid insurance, and being African-American $^{7}$. Seventy-eight percent of the homeless inmates with a severe mental disorder had co-occurring substance-related disorders ${ }^{15,16}$. Homeless patients in the public mental health system were more likely to be reincarcerated than their housed counterparts.

We should note, however, that most studies have focused on mental illness and substance use among those with history of homelessness and incarceration, as opposed to the study of these factors among psychiatric patients. Furthermore, to our knowledge there are no studies in Brazil with a national representative sample. We anticipate common factors with either one but a higher magnitude of potential determinants when patients had a history of both conditions. In this study we examined the association of sociodemographic, clinical, behavioral, and adverse life characteristics with history of homelessness, incarceration or their co-occurrence among psychiatric patients in a multicenter study in Brazil.

\section{Methods}

\section{Design and study population}

This study used data from a cross-sectional multicenter study (PESSOAS Project) conducted in 2006 among users of mental health services in Brazil ${ }^{17}$. The study was designed to assess risk behavior and the seroprevalence of HIV and others STDs among patients with mental illness. In summary a two-stage probability sample was chosen, proportional to the type of care (hospital or outpatient, known as Public Mental Health Outpatient Clinics - CAPS) and the national distribution of reported AIDS cases by region, yielding a total of 2,475 participants. CAPS which only treated substance abuse disorders (CAPS$\mathrm{AD})$ were also excluded from the study. Only adults (18+ years old) and individuals able to provide written informed consent as determined by a mental health professional were eligible for study. A semi-structured person-to-person interview was conducted to obtain sociodemographic, clinical and behavioral data, and psychiatric diagnoses were obtained from medical records. More details about the study design, selection criteria and recruitment methods have been previously published ${ }^{17,18}$. The study was approved by the participating services, by the UFMG Ethical Research committee and by the National Ethical Research Council.

\section{Exposure and outcome measurements}

\section{Outcomes}

We constructed three different outcomes: 1 ) history of homelessness only; 2) history of incarceration only; and, 3) co-occurrence of history of homelessness and incarceration. History of homelessness and incarceration were evaluated 
by these two questions: Have you ever been homelessness? and Have you ever been arrested?. We also asked about reasons and place of arrest. Participants exposed to each of these three outcomes were compared to those with no history of either homelessness or incarceration.

\section{Explanatory variables}

The explanatory variables were divided in three domains as specified below. Sociodemographic characteristics: gender, age (18-39 and $\geq$ 40 years old), skin color (white and non-white), family income in the last month $(\geq 1$ minimum wage and $<1$ minimum wage), schooling $(<5$ and $\geq 5$ years), marital status (married/in union and single/divorced/widower), and current place of residence defined as unstable (living in shelters, hostels, streets, rooms) and stable (living in houses or apartments); Clinical conditions: number of psychiatric diagnoses $(\leq 1$ and $>1)$, main psychiatric diagnoses (ICD-10), previous psychiatric hospitalization (never hospitalized, history of hospitalization and current hospitalized ), age of first hospitalization or treatment in CAPS $(<26$ and $\geq 26$ years old $)$, none or some degree of intellectual disability, self-reported medical comorbidity, and lifetime history of sexually transmitted disease (STD); and, Behavioral and adverse life characteristics: violence exposure, sex under the influence of drugs and/or alcohol, lifetime unsafe sex, lifetime number of partner (abstinent or only one and $>$ one), age of first sexual intercourse (abstinent or $\geq 18$ or $<18$ years old), history of exchange of sex for money, HIV/AIDS knowledge, HIV risk perception, previous HIV testing, lifetime cigarette smoking and substance use exposure. For psychiatric diagnoses, data were abstracted from medical records as registered by a psychiatrist and classified according to the International Classification of Diseases, $10^{\text {th }}$ revision (ICD-10) ${ }^{19}$. Up to three main psychiatric diagnoses were recorded, and hierarchically categorized according to severity as follows: (1) psychotic disorders and depression with psychotic symptoms; (2) bipolar disorder; (3) depression; (4) anxiety; (5) substance use disorders; (6) others. For this analysis, this variable was categorized as: (1) severe mental illness (psychotic disorders, depression with psychotic symptoms, and bipolar disorder), (2) substance use disorders, and (3) others. Violence exposure was categorized in three categories: "none or verbal violence" (defined as having no suffered any type of violence or having ever suffered some type of verbal ag- gression, i.e., threat, humiliation, name calling, offense or embarrassment); "at least physical violence" (defined as experience any kind of physical aggression, including being hit, spanked, or beaten in their lifetime); and "at least sexual violence" (defined as having been forced to have unwanted sexual relation or having suffered any kind of abuse of sexual nature against their will). Lifetime unsafe sex was defined as not always using condoms in all practices. HIV/AIDS knowledge was assessed based on a mean score of 10 questions rated on a 0 to 10 scale by Item Response Theory $^{20}$. HIV risk perception was defined as participants' belief that they were at high risk or low risk of becoming HIV infected. Lifetime cigarette smoking was defined as those who reported smoking at least one regular or hand-rolled cigarette per day during their lifetime. Lifetime substance use exposure was categorized as injecting drug use (IDU), any illicit drug except injecting drugs (such as marijuana, cocaine, crack, hallucinogens, amphetamines, opiates, solvents), only alcohol use, or none.

\section{Statistical analysis}

We generated descriptive characteristics of the sample and the proportion of homelessness, incarceration, the co-occurrence of homelessness and incarceration, and each explanatory variable was reported. For the univariate analysis, differences in proportion were assessed by Pearson chi-square test, and the magnitude of the associations was estimated by the Odds Ratio (OR) with 95\% confidence interval. Participants with a lifetime history of homelessness, incarceration or both were compared, separately, to those without any history of either condition using multinomial logistic regression models. Variables with p-value $\leq 0.20$ in the univariate analysis were used to start intermediate modeling, separately for each domain (i.e., sociodemographics, clinical, and behavioral/adverse life characteristics). The independent effect of potential explanatory variables was assessed by multivariate analysis using multinomial logistic regression. Only variables with $p$-value $\leq 0.10$ remained in each intermediate model and these were modeled together in order to obtain the final adjusted model. A backward deletion strategy was applied and those variables with p-values equal to or less than 0.05 were maintained in each final logistic regression model. Fit of the final model was evaluated using the Hosmer-Lemeshow Test. SAS version 9.4 was used to analyze the data. 


\section{Results}

Descriptive characteristics of the 2,475 participants of the study are presented in Table 1. Most participants were female, age 40 years old or over, reported white skin color, had low education, received treatment at outpatient centers, had a severe mental illness, suffered physical or sexual violence, and $25 \%$ reported use of illicit drugs.

Two hundred and twelve (8.6\%) participants had a history of homelessness only; 405(16.4\%) of incarceration only, and the co-occurrence of homelessness and incarceration were reported by $232(9.4 \%)$ participants. The univariate analyses between explanatory variables and each of these three outcomes are presented in Table 2. We highlight that the likelihood of both conditions (homelessness and incarceration) was higher ( $\mathrm{p}$ $<0.05$ ) among nonwhite men, with a low education level, low family income, and current unstable housing. Both conditions were also positively associated with a more severe mental illness or a substance use disorder, more than one psychiatric diagnosis, history of STD, and current $(\mathrm{OR}=$ $4.57)$ or previous ( $\mathrm{OR}=10.38)$ psychiatric hospitalization. Receiving treatment at a psychiatric hospital at the time of the interview and having been treated for the first time (hospital or CAPS) before 26 years old were also positively associated with both conditions. Physical or sexual violence, sex under the influence of drugs or alcohol, unsafe sex, more than one lifetime sexual partner, and history of exchanging money or drugs for sex were associated with history of homelessness and incarceration. The prevalence of both conditions was also higher among participants who reported poor HIV/Aids knowledge, low HIV/ AIDS risk perception, previous HIV testing, and lifetime use of tobacco (cigarette smoking), alcohol, illicit, and injecting drugs (Table 2).

\section{Multivariate analysis}

Results obtained from the intermediate multivariate models according to each domain (Table 3) indicate markers of poor socioeconomic conditions (lower income, lower schooling, unstable living conditions) associated with either homelessness, incarceration, or both. In addition, nonwhite single/divorced males also were at increased risk of at least one of the conditions analyzed. It should be noted that almost all clinical markers, including number and severity of psychiatric diagnoses, history of STD, previous and early psychiatric hospitalizations, were strongly associated
Table 1. Descriptive characteristics among 2,475 psychiatric patients, PESSOAS Project, Brazil, 2006.

\begin{tabular}{|c|c|}
\hline Characteristics & n $(\%)^{1}$ \\
\hline \multicolumn{2}{|l|}{ Sociodemographic } \\
\hline \multicolumn{2}{|l|}{ Gender: } \\
\hline Women & $1277(51.6)$ \\
\hline Men & $1198(48.4)$ \\
\hline \multicolumn{2}{|l|}{ Age (years old): } \\
\hline$\geq 40$ & $1351(54.6)$ \\
\hline $18-39$ & $1124(45.4)$ \\
\hline \multicolumn{2}{|l|}{ Skin color: } \\
\hline White & $1275(51.5)$ \\
\hline Non-white & $1200(48.5)$ \\
\hline \multicolumn{2}{|c|}{ Family income in the last month ${ }^{2}$ : } \\
\hline$\geq 1$ minimum wage & $1525(64.8)$ \\
\hline$<1$ minimum wage & $827(35.2)$ \\
\hline \multicolumn{2}{|l|}{ Schooling (years): } \\
\hline$\geq 5$ & $1253(50.6)$ \\
\hline$<5$ & $1222(49.4)$ \\
\hline \multicolumn{2}{|l|}{ Marital status: } \\
\hline Married/in union & $821(33.2)$ \\
\hline Single/Divorced/Widower & $1654(66.8)$ \\
\hline \multicolumn{2}{|l|}{ Current place of residence: } \\
\hline Stable & $2165(87.5)$ \\
\hline Unstable & $310(12.5)$ \\
\hline \multicolumn{2}{|l|}{ Clinical } \\
\hline \multicolumn{2}{|c|}{ Number of psychiatric diagnoses: } \\
\hline$\leq 1$ & $1357(54.8)$ \\
\hline$>1$ & $1118(45.2)$ \\
\hline \multicolumn{2}{|l|}{ Psychiatric diagnoses (ICD-10): } \\
\hline Other & $945(38.2)$ \\
\hline Severe mental illness & $1413(57.1)$ \\
\hline Substance use disorders & $117(4.7)$ \\
\hline \multicolumn{2}{|l|}{ Hospitalization: } \\
\hline Never & $788(31.8)$ \\
\hline History of hospitalization & $789(31.9)$ \\
\hline Current hospitalized & $898(36.3)$ \\
\hline \multicolumn{2}{|l|}{$\begin{array}{l}\text { Age of first hospitalization or } \\
\text { treatment in CAPS (years old): }\end{array}$} \\
\hline$\geq 26$ & $1289(60.6)$ \\
\hline$<26$ & $837(39.4)$ \\
\hline \multicolumn{2}{|c|}{ Any degree of intellectual disability: } \\
\hline None & $1722(69.9)$ \\
\hline Some & $741(30.1)$ \\
\hline \multicolumn{2}{|c|}{ Self-reported medical co morbidity: } \\
\hline No & $1342(54.8)$ \\
\hline Yes & $1109(45.2)$ \\
\hline \multicolumn{2}{|l|}{ Lifetime history of STD ${ }^{4}$ : } \\
\hline No & $1873(76.7)$ \\
\hline Yes & $568(23.3)$ \\
\hline
\end{tabular}


Table 1. Descriptive characteristics among 2,475 psychiatric patients, PESSOAS Project, Brazil, 2006.

\begin{tabular}{|c|c|}
\hline Characteristics & n $(\%)^{1}$ \\
\hline \multicolumn{2}{|l|}{ Behavior and Adverse life events } \\
\hline \multicolumn{2}{|l|}{ Violence exposure: } \\
\hline None or verbal violence only & $958(38.7)$ \\
\hline At least psychical violence & $1029(41.5)$ \\
\hline At least sexual violence & $488(19.7)$ \\
\hline \multicolumn{2}{|l|}{$\begin{array}{l}\text { Sex under the influence of drugs } \\
\text { and/ or alcohol: }\end{array}$} \\
\hline No & $1475(68.4)$ \\
\hline Yes & $681(31.6)$ \\
\hline \multicolumn{2}{|l|}{ Lifetime unsafe sex: } \\
\hline No & $482(19.7)$ \\
\hline Yes & $1970(80.3)$ \\
\hline \multicolumn{2}{|l|}{ Lifetime number of partner: } \\
\hline Abstinent or only 1 & $805(32.5)$ \\
\hline$>1$ & $1523(61.5)$ \\
\hline \multicolumn{2}{|l|}{$\begin{array}{l}\text { Age of first sexual intercourse (years } \\
\text { old): }\end{array}$} \\
\hline Abstinent or $\geq 18$ & $1282(51.8)$ \\
\hline$<18$ & $1193(48.2)$ \\
\hline \multicolumn{2}{|l|}{$\begin{array}{l}\text { History of exchange of sex for } \\
\text { money: }\end{array}$} \\
\hline No & $1811(73.6)$ \\
\hline Yes & $648(26.4)$ \\
\hline \multicolumn{2}{|l|}{ HIV/Aids Knowledge: } \\
\hline Good & $1354(55.3)$ \\
\hline Poor & $1095(44.7)$ \\
\hline \multicolumn{2}{|l|}{ HIV risk perception: } \\
\hline Low & $1390(59.2)$ \\
\hline High & $957(40.8)$ \\
\hline \multicolumn{2}{|l|}{ Previous HIV testing: } \\
\hline No & $1807(73.0)$ \\
\hline Yes & $668(27.0)$ \\
\hline \multicolumn{2}{|l|}{ Lifetime cigarette smoking: } \\
\hline No & $701(28.5)$ \\
\hline Yes & $1762(71.5)$ \\
\hline \multicolumn{2}{|l|}{ Lifetime substance use exposure: } \\
\hline None & $805(32.5)$ \\
\hline Only alcohol & $1043(42.1)$ \\
\hline $\begin{array}{l}\text { Any illicit drug except injecting } \\
\text { drugs }\end{array}$ & $555(22.4)$ \\
\hline Injecting drug use & $72(2.9)$ \\
\hline
\end{tabular}

$(\mathrm{p}<.05)$ with all the outcomes. Similarly, most behavior and adverse life events, including having suffered violence, substance use, multiple sex partners, exchange of sex for money/drugs, and cigarette smoking, were also associated with the three outcomes of interest.

Final multivariate models for each comparison can be seen in Table 4. When taking together and comparing the final models, many characteristics were independently associated $(p<0.05)$ with homelessness only (e.g. lower income, living in unstable condition, intellectual disability, cigarette smoking) or incarceration only (e.g. male gender, lower schooling, sex under the effect of alcohol/drugs, multiple sex partners), while a few variables were associated with both conditions (e.g. psychiatric hospitalizations, substance use, and history of STDs, sexual, physical, or verbal violence). In addition, the magnitude of the associations of selected variables was much higher among patients with the co-occurrence of both conditions, including physical violence $(\mathrm{OR}=$ $4.69)$, sexual violence $(\mathrm{OR}=5.18)$, sex under the influence of alcohol/drugs ( OR = 2.12), multiple lifetime sexual partner $(\mathrm{OR}=4.41)$, lifetime cigarette smoking $(\mathrm{OR}=2.72)$, and any illicit drug $(\mathrm{OR}=4.31)$ or injecting drug use $(\mathrm{OR}=12.22)$.

\section{Discussion}

The association of sociodemographic, clinical, behavioral, and adverse life characteristics with the events studied indicated a high proportion of patients who experienced homelessness (8.6\%), incarceration (16.4\%) and the co-occurrence of homelessness and incarceration (9,4\%) in their lifetime. Hawthorne et al. ${ }^{7}$ found that $11.5 \%$ of public mental health patients in the USA had been incarcerated during a one-year period and 9.4\% were homelessness, while Cuellar et al. ${ }^{6}$, also in the USA, found $24.0 \%$ of history of incarceration during a ten-year period ${ }^{6,7}$. In one of the few studies that have assessed the co-occurrence of both conditions, Hawthorne et al. ${ }^{7}$ indicate $3.5 \%$ in a one-year period, lower than our results $(9.4 \%)^{7}$. However, we should note that our data refer to lifetime experience, and these data are not necessarily comparable.

Consistent with previous research that evaluated incarceration and homelessness as separate outcomes s, $^{3,21-23}$, we found that being male was associated with incarceration and co-occurrence of homelessness and incarceration. Our results also evidenced that the exposure to social adversity, characterized by low income, low education and living in unstable housing, were strongly associated with the co-occurrence of homelessness and incarceration; and at least one indicator of 


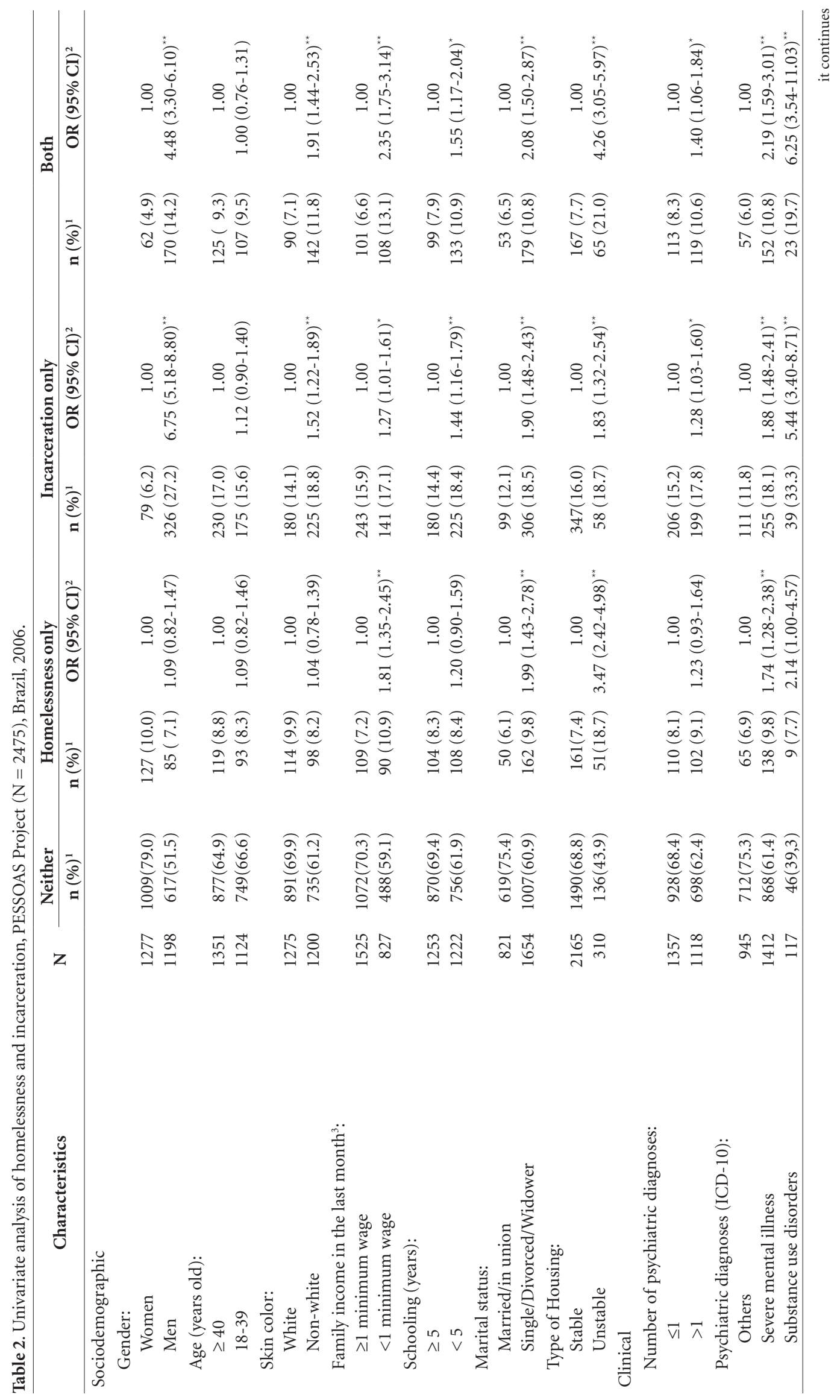




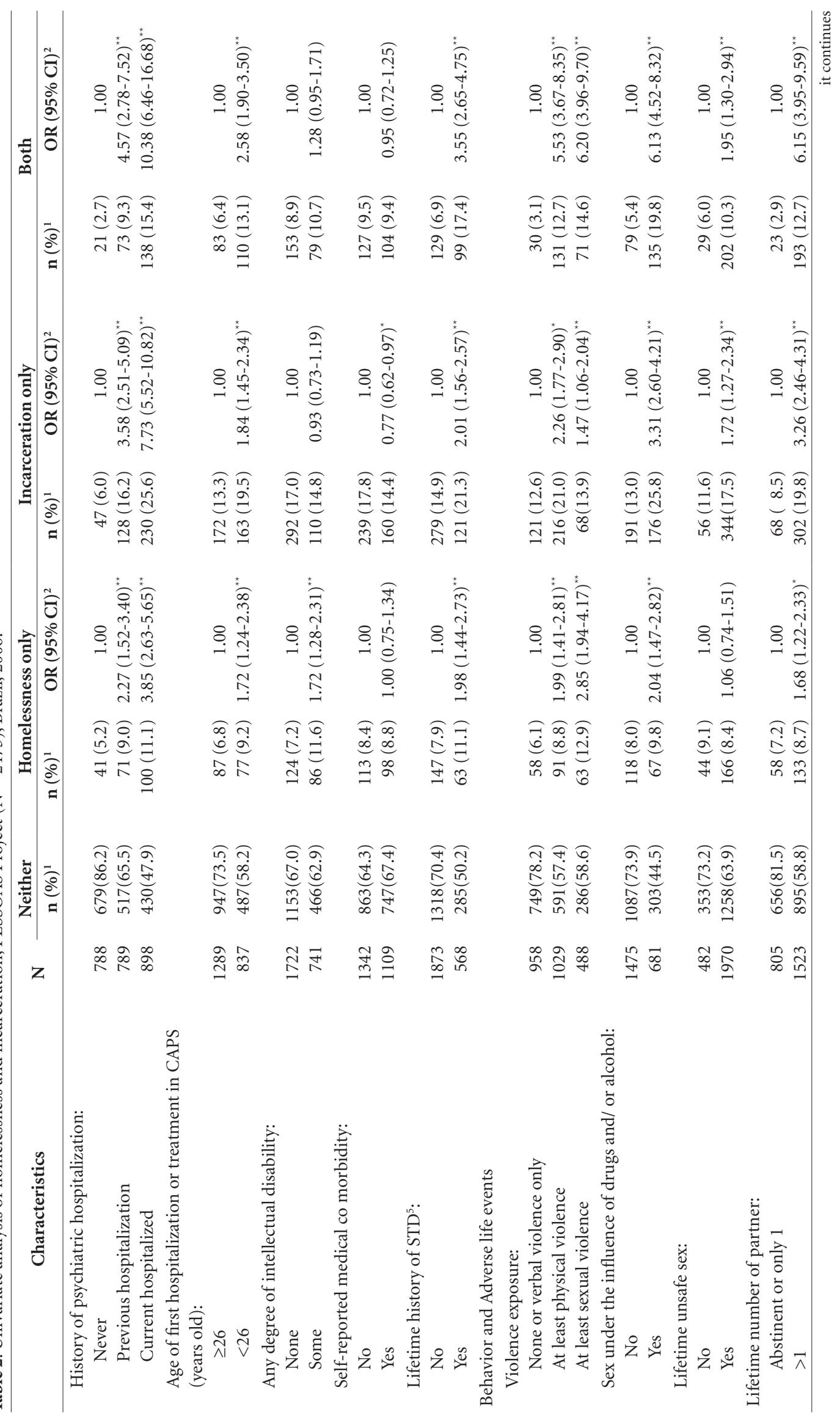




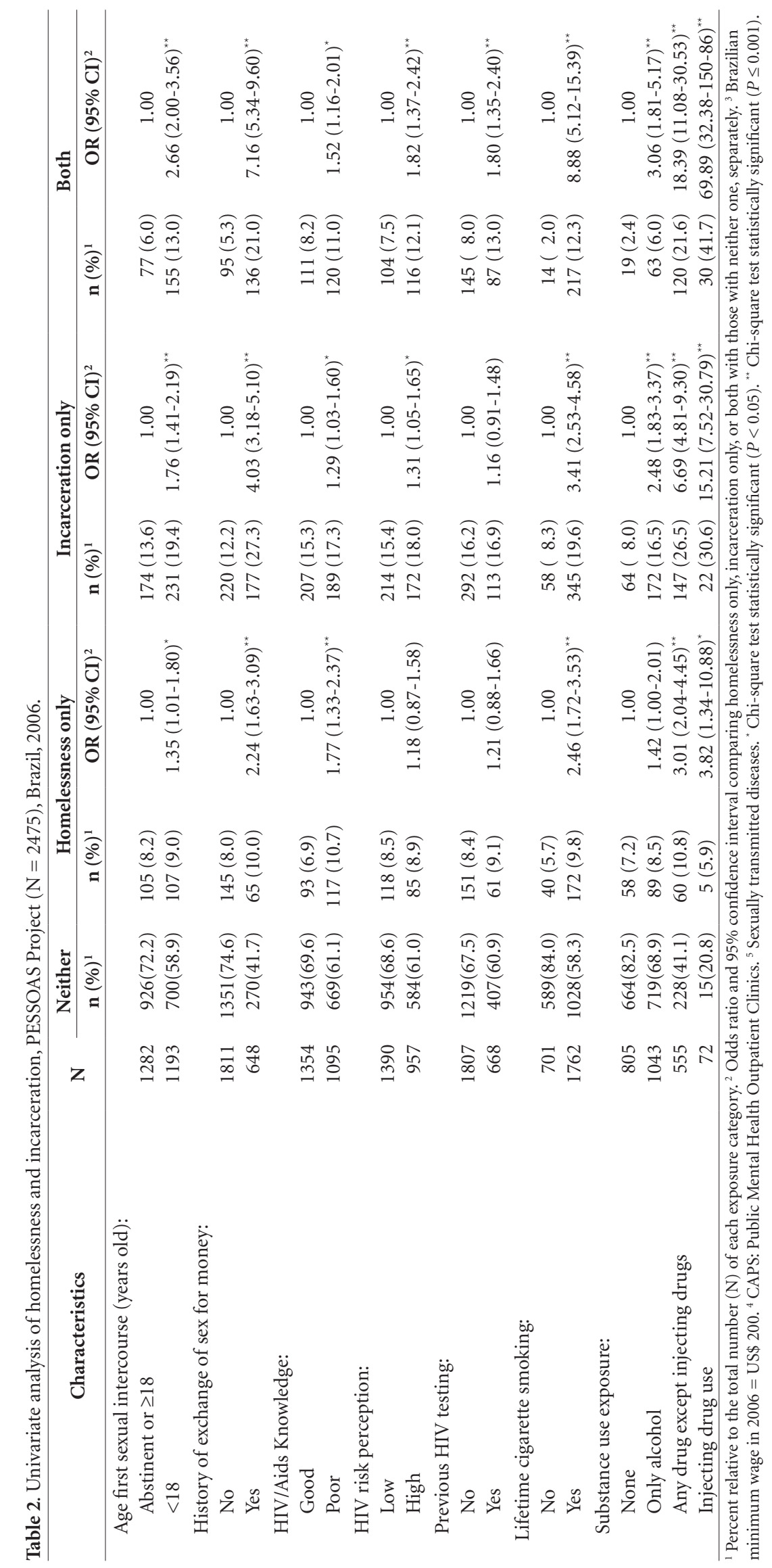


Table 3. Intermediate multivariate analyses of homelessness and incarceration according to each domain, PESSOAS Project $(\mathrm{N}=2,475)$, Brazil, 2006.

\begin{tabular}{|c|c|c|c|}
\hline \multirow{2}{*}{ Characteristics } & \multirow{2}{*}{$\begin{array}{c}\text { Only homelessness } \\
\text { OR }(95 \% \mathrm{CI})^{2}\end{array}$} & \multirow{2}{*}{$\begin{array}{c}\text { Only incarceration } \\
\text { OR }(95 \% \mathrm{CI})^{2}\end{array}$} & \multirow{2}{*}{$\begin{array}{c}\text { Both } \\
\text { OR }(95 \% \mathrm{CI})^{2} \\
\end{array}$} \\
\hline & & & \\
\hline \multicolumn{4}{|l|}{ Domain 1 - Sociodemographic } \\
\hline \multicolumn{4}{|l|}{ Gender: } \\
\hline Women & & 1.00 & 1.00 \\
\hline Men & & $6.34(4.84-8.29)^{* *}$ & $3.99(2.90-5.47)^{* *}$ \\
\hline \multicolumn{4}{|l|}{ Skin color: } \\
\hline White & & 1.00 & 1.00 \\
\hline Non-white & & $1.43(1.13-1.81)^{*}$ & $1.79(1.33-2.41)^{* *}$ \\
\hline \multicolumn{4}{|l|}{ Family income in the last month ${ }^{3}$ : } \\
\hline$\geq 1$ minimum wage & 1.00 & & 1.00 \\
\hline$<1$ minimum wage & $1.39(1.01-1.91)^{*}$ & & $1.90(1.38-2.60)^{* *}$ \\
\hline \multicolumn{4}{|l|}{ Schooling (years): } \\
\hline$\geq 5$ & & 1.00 & \\
\hline$<5$ & & $1.41(1.11-1.78)^{*}$ & \\
\hline \multicolumn{4}{|l|}{ Marital status: } \\
\hline Married/in union & 1.00 & 1.00 & \\
\hline Single/Divorced/Widower & $1.68(1.19-2.36)^{*}$ & $1.43(1.09-186)^{*}$ & \\
\hline \multicolumn{4}{|l|}{ Type of Housing: } \\
\hline Stable & 1.00 & & 1.00 \\
\hline Unstable & $2.72(1.85-3.99)^{* *}$ & & $2.66(1.84-3.85)^{* *}$ \\
\hline \multicolumn{4}{|l|}{ Domain 2 - Clinical } \\
\hline \multicolumn{4}{|l|}{ Number of psychiatric diagnoses: } \\
\hline$\leq 1$ & & 1.00 & 1.00 \\
\hline$>1$ & & $1.32(1.04-1.68)^{*}$ & $1.43(1.04-1.95)^{*}$ \\
\hline \multicolumn{4}{|l|}{ Psychiatric diagnoses (ICD-10): } \\
\hline Others & & 1.00 & 1.00 \\
\hline Severe mental illness & & $1.17(0.90-1.54)$ & $1.34(0.94-1.92)$ \\
\hline Substance use disorders & & $2.78(1.65-4.73)^{* *}$ & $3.89(1.99-7.59)^{* *}$ \\
\hline \multicolumn{4}{|c|}{ History of psychiatric hospitalization: } \\
\hline Never & 1.00 & 1.00 & 1.00 \\
\hline Previous hospitalization & $1.76(1.14-2.72)^{*}$ & $2.88(1.96-4.23)^{* *}$ & $2.84(1.65-4.90)^{* *}$ \\
\hline Current hospitalized & $3.36(2.24-5.05)^{* *}$ & $6.17(4.28-8.91)^{* *}$ & $7.17(4.28-12.02)^{* *}$ \\
\hline \multicolumn{4}{|c|}{$\begin{array}{l}\text { Age of first hospitalization or treatment in } \\
\text { CAPS (years old): }\end{array}$} \\
\hline$\geq 26$ & 1.00 & 1.00 & 1.00 \\
\hline$<26$ & $1.35(0.96-1.92)$ & $1.37(1.05-1.79)^{*}$ & $1.84(1.31-2.60)^{* *}$ \\
\hline \multicolumn{4}{|l|}{ Any degree of intellectual disability: } \\
\hline None & 1.00 & & 1.00 \\
\hline Some & $1.46(1.07-2.00)^{*}$ & & $1.39(1.00-1.94)$ \\
\hline \multicolumn{4}{|l|}{ Lifetime history of STD ${ }^{5}$ : } \\
\hline No & 1.00 & 1.00 & 1.00 \\
\hline Yes & $2.24(1.60-3.13)^{* *}$ & $2.15(1.65-2.81)^{* *}$ & $4.24(3.07-5.86)^{* *}$ \\
\hline \multicolumn{4}{|c|}{ Domain 3 - Behavior and Adverse life events } \\
\hline \multicolumn{4}{|c|}{ Violence exposure: } \\
\hline None or verbal violence only & 1.00 & 1.00 & 1.00 \\
\hline At least physical violence & $1.74(1.21-2.50)^{*}$ & $1.55(1.16-2.08)^{*}$ & $3.74(2.24-6.27)^{* *}$ \\
\hline At least sexual violence & $2.65(1.77-3.95)^{* *}$ & $1.03(0.71-1.50)$ & $3.63(2.05-6.44)^{* *}$ \\
\hline \multicolumn{4}{|c|}{$\begin{array}{l}\text { Sex under the influence of drugs and/ or } \\
\text { alcohol: }\end{array}$} \\
\hline No & & 1.00 & 1.00 \\
\hline Yes & & $1.75(1.33-2.32)^{* *}$ & $2.23(1.53-3.27)^{* *}$ \\
\hline
\end{tabular}


Table 3. Intermediate multivariate analyses of homelessness and incarceration according to each domain, PESSOAS Project $(\mathrm{N}=2,475)$, Brazil, 2006.

\begin{tabular}{|c|c|c|c|}
\hline \multirow{2}{*}{ Characteristics } & Only homelessness & Only incarceration & Both \\
\hline & OR $(95 \% \mathrm{CI})^{2}$ & OR $(95 \% \mathrm{CI})^{2}$ & OR $(95 \% \mathrm{CI})^{2}$ \\
\hline \multicolumn{4}{|l|}{ Lifetime number of partner: } \\
\hline Abstinent or only 1 & & 1.00 & 1.00 \\
\hline$>1$ & & $2.29(1.52-3.43)^{* *}$ & $3.81(1.77-8.23)^{* *}$ \\
\hline \multicolumn{4}{|l|}{ History of exchange of sex for money: } \\
\hline No & 1.00 & 1.00 & 1.00 \\
\hline Yes & $1.49(1.04-2.14)^{*}$ & $2.05(1.56-2.70)^{* *}$ & $2.21(1.52-3.22)^{* *}$ \\
\hline \multicolumn{4}{|l|}{ HIV/Aids Knowledge: } \\
\hline Good & 1.00 & 1.00 & 1.00 \\
\hline Poor & $2.01(1.48-2.73)^{\star *}$ & $1.51(1.16-1.96)^{*}$ & $2.30(1.58-3.36)^{* *}$ \\
\hline \multicolumn{4}{|l|}{ HIV risk perception: } \\
\hline Low & & & 1.00 \\
\hline High & & & $1.63(1.13-2.34)^{*}$ \\
\hline \multicolumn{4}{|l|}{ Lifetime cigarette smoking: } \\
\hline No & 1.00 & 1.00 & 1.00 \\
\hline Yes & $1.77(1.21-2.60)^{*}$ & $1.80(1.26-2.58)^{* *}$ & $3.09(1.56-6.10)^{* *}$ \\
\hline \multicolumn{4}{|l|}{ Substance use exposure: } \\
\hline None & 1.00 & 1.00 & 1.00 \\
\hline Only alcohol & $1.15(0.80-1.67)$ & $1.35(0.93-1.95)$ & $1.45(0.73-2.88)$ \\
\hline Any drug except injecting drugs & $2.15(1.37-3.38)^{* *}$ & $2.49(1.63-3.79)^{* *}$ & $5.04(2.52-10.07)^{* *}$ \\
\hline Injecting drug use & $2.02(0.66-6.15)$ & $3.88(1.75-8.61)^{* *}$ & $11.58(4.38-30.58)^{* *}$ \\
\hline \multicolumn{4}{|l|}{ HIV risk perception: } \\
\hline Low & & & 1.00 \\
\hline High & & & $1.63(1.13-2.34)^{*}$ \\
\hline \multicolumn{4}{|l|}{ Lifetime cigarette smoking: } \\
\hline No & 1.00 & 1.00 & 1.00 \\
\hline Yes & $1.77(1.21-2.60)^{*}$ & $1.80(1.26-2.58)^{* *}$ & $3.09(1.56-6.10)^{* *}$ \\
\hline \multicolumn{4}{|l|}{ Substance use exposure: } \\
\hline None & 1.00 & 1.00 & 1.00 \\
\hline Only alcohol & $1.15(0.80-1.67)$ & $1.35(0.93-1.95)$ & $1.45(0.73-2.88)$ \\
\hline Any drug except injecting drugs & $2.15(1.37-3.38)^{* *}$ & $2.49(1.63-3.79)^{* *}$ & $5.04(2.52-10.07)^{* *}$ \\
\hline Injecting drug use & $2.02(0.66-6.15)$ & $3.88(1.75-8.61)^{* *}$ & $11.58(4.38-30.58)^{* *}$ \\
\hline
\end{tabular}

socioeconomic circumstance remained associated with homelessness and incarceration when these outcomes were analyzed separately. People with mental illness are often contextualized in disadvantaged social settings ${ }^{1,24}$. Previous studies also reported associations of socioeconomic position with incarceration and homelessness among people with mental illness ${ }^{1,21,22,25}$. Being non-white was associated with higher chances of incarceration and the co-occurrence of incarceration and homelessness in the present study after adjusting for socioeconomic position (income and education) in the intermediate models. However, this association did not remain statistically significant in the final models, contrary to previous studies ${ }^{3,7,23,26,27}$. Although the reason for this difference is not clear, we should point out that these previous studies were carried out in the United States, and less is known about the association of race with incarceration and homelessness in psychiatric patients in settings marked by higher racial miscegenation such as in Brazil ${ }^{28,29}$. Thus, contextual factors related to different ways of living determined as by race may partially explain our results. In addition, methodological issues such as statistical power and study design could also be possible explanations. Furthermore, because variables considered in the final models vary across the studies, comparability is limited. Nevertheless, further studies are needed for a better understanding of homelessness and incarceration in different racial contexts. 
Table 4. Final Multivariate models of homelessness and incarceration, PESSOAS Project $(\mathrm{N}=2,475)$, Brazil, 2006.

\begin{tabular}{|c|c|c|c|}
\hline \multirow{2}{*}{ Characteristics } & Only homelessness & Only incarceration & Both \\
\hline & OR $(95 \% \mathrm{CI})^{2}$ & OR $(95 \% \mathrm{CI})^{2}$ & OR $(95 \% \mathrm{CI})^{2}$ \\
\hline \multicolumn{4}{|l|}{ Sociodemographic } \\
\hline \multicolumn{4}{|l|}{ Gender: } \\
\hline Women & & 1.00 & 1.00 \\
\hline Men & & $5.04(3.65-6.96)^{* *}$ & $2.39(1.49-3.83)^{* *}$ \\
\hline \multicolumn{4}{|c|}{ Family income in the last month ${ }^{3}$ : } \\
\hline$\geq 1$ minimum wage & 1.00 & & 1.00 \\
\hline$<1$ minimum wage & $1.44(1.02-2.04)^{*}$ & & $3.63(2.34-5.65)^{* *}$ \\
\hline \multicolumn{4}{|l|}{ Schooling (years): } \\
\hline$\geq 5$ & & 1.00 & 1.00 \\
\hline$<5$ & & $2.03(1.53-2.69)^{* *}$ & $3.22(2.08-5.01)^{* *}$ \\
\hline \multicolumn{4}{|l|}{ Type of Housing: } \\
\hline Stable & 1.00 & & 1.00 \\
\hline Unstable & $2.31(1.48-3.61)^{* *}$ & & $3.25(1.79-5.90)^{* *}$ \\
\hline \multicolumn{4}{|l|}{ Clinical } \\
\hline \multicolumn{4}{|c|}{ Psychiatric diagnoses (ICD-10): } \\
\hline Others & & & 1.00 \\
\hline Severe mental illness & & & $1.67(1.03-2.70)^{*}$ \\
\hline Substance use disorders & & & $1.69(0.74-3.87)$ \\
\hline \multicolumn{4}{|l|}{ History of psychiatric } \\
\hline Never & 1.00 & 1.00 & 1.00 \\
\hline Previous hospitalization & $1.68(1.10-2.57)^{*}$ & $2.29(1.54-3.40)^{* *}$ & $1.97(1.02-3.81)^{*}$ \\
\hline Current hospitalized & $2.15(1.39-3.33)^{* *}$ & $4.85(3.29-7.14)^{* *}$ & $2.34(1.20-4.58)^{*}$ \\
\hline \multicolumn{4}{|c|}{ Any degree of intellectual disability: } \\
\hline None & 1.00 & & \\
\hline Some & $1.40(1.00-1.97)$ & & \\
\hline \multicolumn{4}{|l|}{ Lifetime history of STD ${ }^{5}$ : } \\
\hline No & 1.00 & 1.00 & 1.00 \\
\hline Yes & $1.88(1.32-2.68)^{* *}$ & $1.66(1.22-2.26)^{* *}$ & $1.95(1.26-3.03)^{*}$ \\
\hline
\end{tabular}

Participants with severe mental illness (psychotic disorders, depression with psychotic symptoms, and bipolar disorder) were $67 \%$ more likely of having a history of co-occurrence of homelessness and incarceration, and we should note that this association was not present when assessing homelessness or incarceration separately. This finding is important to promote mental health policies for the protection of patients with severe mental disorders, since they may indicate increased vulnerability in these groups of patients. Similarly, Hawthorne et al. found that patients with schizophrenia, bipolar, or other psychotic disorder diagnoses have been associated with incarceration ${ }^{7}$.

We have also found that history of previous hospitalization and being current hospitalized were associated with higher chances of having the three outcomes. Previous studies have also shown that psychiatric hospitalizations and the use of emergency psychiatric unit are more frequent among patients with mental illness who have history of homelessness ${ }^{3,26}$ or incarceration $^{30}$. Patients under an acute psychiatric episode and clinical destabilization with increased severity of symptoms, which often require hospitalization, are potentially more vulnerable to criminality and homelessness ${ }^{31}$. Studies have demonstrated that routine outpatient services and high psychiatric medication access reduce the chances of arrest among individuals with mental illness ${ }^{32,33}$. These evidences show that the ability of the mental health system to deliver and coordinate psychiatric treatment in outpatient 
Table 4. Final Multivariate models of homelessness and incarceration, PESSOAS Project $(\mathrm{N}=2,475)$, Brazil, 2006.

\begin{tabular}{|c|c|c|c|}
\hline \multirow{2}{*}{ Characteristics } & Only homelessness & Only incarceration & Both \\
\hline & OR $(95 \% \mathrm{CI})^{2}$ & OR $(95 \% \mathrm{CI})^{2}$ & OR $(95 \% \mathrm{CI})^{2}$ \\
\hline \multicolumn{4}{|l|}{ Behavior and Adverse life events } \\
\hline \multicolumn{4}{|l|}{ Violence exposure: } \\
\hline None or verbal violence only & 1.00 & 1.00 & 1.00 \\
\hline At least physical violence & $1.62(1.12-2.35)^{*}$ & $1.96(1.44-2.69)^{* *}$ & $4.69(2.62-8.40)^{* *}$ \\
\hline At least sexual violence & $2.35(1.56-3.54)^{* *}$ & $1.68(1.11-2.53)^{*}$ & $5.18(2.63-10.20)^{* *}$ \\
\hline \multicolumn{4}{|l|}{ Sex under the influence of drugs and/ } \\
\hline No & & $1.41(1.04-1.91)^{*}$ & $2.12(1.37-3.29)^{* *}$ \\
\hline \multicolumn{4}{|l|}{ Yes } \\
\hline \multicolumn{4}{|l|}{ Lifetime number of partners: } \\
\hline Abstinent or only 1 & & 1.00 & 1.00 \\
\hline$>1$ & & $1.73(1.14-2.64)^{*}$ & $4.41(1.77-11.00)^{* *}$ \\
\hline \multicolumn{4}{|l|}{ History of exchange of sex for } \\
\hline money: & & & 1.00 \\
\hline No & & & $1.73(1.12-2.68)^{*}$ \\
\hline \multicolumn{4}{|l|}{ Yes } \\
\hline \multicolumn{4}{|l|}{ HIV/Aids Knowledge: } \\
\hline Good & 1.00 & & \\
\hline Poor & $1.44(1.03-2.02)^{*}$ & & \\
\hline \multicolumn{4}{|l|}{ HIV risk perception: } \\
\hline Low & & & 1.00 \\
\hline High & & & $1.70(1.13-2.57)^{\star}$ \\
\hline \multicolumn{4}{|l|}{ Lifetime cigarette smoking: } \\
\hline No & 1.00 & & 1.00 \\
\hline Yes & $1.63(1.10-2.42)^{*}$ & & $2.72(1.27-5.83)^{*}$ \\
\hline \multicolumn{4}{|l|}{ Substance use exposure: } \\
\hline None & 1.00 & 1.00 & 1.00 \\
\hline Only alcohol & $1.41(0.96-2.08)$ & $1.09(0.74-1.61)$ & $1.40(0.65-2.99)$ \\
\hline Any drug except injecting drugs & $2.65(1.67-4.19)^{* *}$ & $1.84(1.18-2.86)^{*}$ & $4.31(1.97-9.40)^{* *}$ \\
\hline Injecting drug use & $2.76(0.88-8.66)$ & $3.46(1.47-8.13)^{*}$ & $12.22(4.07-36.64)^{* *}$ \\
\hline
\end{tabular}

services, including the provision of easy access to medication, can act as a primary prevention approach to decrease rates of homelessness and incarceration among mental illness patients.

Exposure to violence was strongly associated with the three outcomes, especially staggering higher chances of sexual and physical violence among those with history of co-occurrence of homelessness and incarceration. Adverse socioeconomic conditions (low income and low education) coincide with violence. Residents of poor areas are more vulnerable to violent crimes worldwide, including assault and rape ${ }^{24}$. Noxious family environments are also related to violence. Patients in acute psychiatric crisis can behave aggressively, increasing their vulnerability to homelessness and incarceration. The high magnitude of the association in the co-occurrence of both outcomes suggests that such interpretation is plausible. Nevertheless, the cross-sectional design of our study cannot rule out a potential reverse causality: patients may have experienced violence when they were in prison or living on the streets. Wolff \& Shy ${ }^{13}$, for instance, presented high rates of sexual victimization among incarcerated men and women in the USA. Sexual violence in prison includes inmate-on-inmate and staff-on-inmate sexual victimization and is related to behaviors varying from sexually misconduct to sexual assaults $^{34}$.

Our results also corroborate the hypothesis regarding the relationship between homelessness and incarceration and history of risky sexual activities and substance use. Sex under the influ- 
ence of alcohol or illicit drugs, lifetime number of partners and history of exchange sex for money were strongly associated with the co-occurrence of both conditions. Previous studies reported high rates of sexual exploration, unplanned pregnancy, unprotected sex, and multiple sexual partners among homeless and incarcerated individuals ${ }^{34,35}$. It is possible that non-consensual or unwanted sexual practices are connected to the context of the patients' lives. In fact, selling sex to meet subsistence needs (survival sex) has been frequently observed among the homeless ${ }^{36}$. Moreover, the social groups to which individuals belong are crucial to explain these outcomes. Patients from family environments marked by abuse, neglect, or caregiver substance use are more likely to engage in risky behaviors in adulthood. Lack of family support also seems to play a decisive role after leaving home. Having a close family member seems to protect against risk taking $^{36}$. In summary, exposure to violence, risky sexual practices and substance use may be part of a cluster of vulnerability to homelessness and incarceration shared by Brazilian patients with mental illness.

Despite the relevance and magnitude of our results, some limitations must be pointed out. First, our results may not be generalizable to all psychiatric patients in Brazil because of the exclusion of more severely ill patients and those who did not have capacity to consent to participation in the study. In addition, the cross-sectional design limits our capacity to establish definite cause-effect relationships. We did not direct- ly assess psychiatric diagnoses or symptoms, but rather obtained these data from medical charts. It is possible that the prevalence of history of homelessness incarceration, and the co-occurrence of both in this population may be underestimated because of the exclusion of Public Mental Health Outpatient Clinics for substance use disorders (CAPS-AD) from the study, which have a higher concentration of patients with substance use disorder and/or IDU. However, we should note that the present study is the first known national representative study to assess potential factors associated with history of homelessness, incarceration and the co-occurrence of both conducted in a national sample of psychiatric patients in public mental health care in Brazil.

In conclusion, the current study showed that history of incarceration and homelessness among psychiatric patients in Brazil are strongly correlated, and they share many associated factors, such as socioeconomic disadvantage, severe psychiatric conditions, exposure to violence, unsafe sexual behavior, and drug use. Our findings have implications in efforts to reduce the likelihood of criminal arrest and homelessness episodes among psychiatric patients, because many of these associated factors are potentially modifiable. Thus, integrated care as well as intersectoral actions for addressing social adversities, and reduce exposure to illicit drugs and violence in this extremely vulnerable population must be considered at the health, judiciary, and social department levels. The implementation of these integrated policies is urgently needed in Brazil.

\section{Collaborations}

APS Melo and MDC Guimarães, worked on the conception, delineation, application of instruments, analysis and interpretation of the data and writing and review of the report. LV Camelo, FCR Barros, EP Lima, worked on the analysis and interpretation of the data and writing of the article. 


\section{Acknowledgments}

Financing of this project was provided by The Brazilian National STD/AIDS Program, Ministry of Health. LV Camelo was supported by CAPES postdoctoral research fellow. MDC Guimarães was CNPq research fellow during the preparation of this manuscript.

\section{References}

1. Draine J, Salzer MS, Culhane DP, Hadley TR. Role of social disadvantage in crime, joblessness, and homelessness among persons with serious mental illness. Psychiatr Serv 2002; 53(5):565-573.

2. Junginger J, Claypoole K, Laygo R, Crisanti A. Effects of Serious Mental Illness and Substance Abuse on Criminal Offenses. Psychiatr Serv 2006; 57(6):879-882.

3. Folsom D, Hawthorne W, Lindamer L, Gilmer T, Bailey A, Golshan S, Garcia P, Unützer J, Hough R, Jeste DV. Prevalence and Risk Factors for Homelessness and Utilization of Mental Health Services Among 10,340 Patients With Serious Mental Illness in a Large Public Mental Health System. Am J Psychiatry 2005; 162(2):370-376

4. Greenberg GA, Rosenheck RA. Jail incarceration, homelessness, and mental health: a national study. Psychiatr Serv 2008; 59(2):170-177.

5. Burt M, Aron LY, Douglas T, Valente J, Lee E, Iwen B. Homelessness: Programs and people they serve. Washington: Urban Institute; 1999.

6. Cuellar A, Snowden L, Ewing T. Criminal Records of Persons Served in the Public Mental Health System. Psychiatr Serv 2007; 58(1):114-120.

7. Hawthorne W, Folsom D, Sommerfeld D, Lanouette N, Lewis M, Aarons G, Conklin RM, Solorzano E, Lindamer LA, Jeste DV. Incarceration Among Adults Who Are in the Public Mental Health System: Rates, Risk Factors, and Short-Term Outcomes. Psychiatr Serv 2012; 63(1):26-32.

8. Midgley B. Achieving just outcomes for homeless people through the court process. Journal of Judicial Administration 2005; 15:82-106.

9. White M, Chafetz L, Collins-Bride G, Nickens J. History of arrest, incarceration and victimization in community-based severely mentally ill. J Community Health 2006; 31(2):123-135.

10. Rosenheck R, Fontana A. A model of homelessness among male veterans of the Vietnam-War generation. Am J Psychiatry 1994; 151(3):421-427.

11. Weiser SD, Neilands TB, Comfort ML, Dilworth SE, Cohen J, Tulsky JP, Riley ED. Gender Specific Correlates of Incarceration Among Marginally Housed Individuals in San Francisco. Am J Public Health 2009; 99(8):1459-1463.

12. Saddichha S, Fliers J, Frankish J, Somers J, Schuetz C, Krausz M. Homeless and incarcerated: An epidemiological study from Canada. Int J Soc Psychiatry 2014; 60(8):795-800.

13. Wolff N, Shi J. Contextualization of Physical and Sexual Assault in Male Prisons: Incidents and Their Aftermath. J Correct Health Care 2009; 15(1):58-82.

14. Baggett TP, Hwang SW, O'Connell JJ, Porneala BC, Stringfellow EJ, Orav EJ, Singer DE, Rigotti NA. Mortality Among Homeless Adults in Boston: Shifts in Causes of Death Over a 15-year Period. JAMA Intern Med 2013; 173(3):189-195.

15. McNiel D, Binder R, Robinson J. Incarceration Associated With Homelessness, Mental Disorder, and Co-occurring Substance Abuse. Psychiatr Serv 2005; 56(7):840-846. 
16. Luciano A, Belstock J, Malmberg P, McHugo GJ, Drake RE, Xie H, Essock SM, Covell NH. Predictors of incarceration among urban adults with co-occurring severe mental illness and a substance use disorder. Psychiatr Serv 2014; 65(11):1325-1331.

17. Guimarães M, Campos L, Melo A, Carmo R, Machado C, Acurcio F. Prevalence of HIV, syphilis, hepatitis B and $\mathrm{C}$ among adults with mental illness: a multicenter study in Brazil. Rev. Bras. Psiquiatr 2009; 31(1):43-47.

18. Guimarães MD, Oliveira HN, Campos LN, Santos CA, Gomes CE, Oliveira SB, Freitas MI, Acúrcio FA, Machado CJ. Reliability and validity of a questionnaire on vulnerability to sexually transmitted infections among adults with chronic mental illness: PESSOAS Project. Rev. Bras. Psiquiatr 2008; 30(1):55-59.

19. World Health Organizations (WHO). International statistical classification of diseases and related health problems. $10^{\text {th }}$ revision, edition. Geneva: WHO; 2010.

20. Melo A, César C, Assis Acurcio F, Campos L, Graças Braga Ceccato M, Wainberg M, McKinnon K, Guimarães MD. Individual and Treatment Setting Predictors of HIV/AIDS Knowledge Among Psychiatric Patients and Their Implications In a National Multisite Study in Brazil. Community Ment Health J 2010; 46(5):505-516.

21. Compton SN, Swanson JW, Wagner HR, Swartz MS, Burns BJ, Elbogen EB. Involuntary outpatient commitment and homelessness in persons with severe mental illness. Ment Health Serv Res 2003; 5(1):2738.

22. Lauber C, Lay B, Rössler W. Homelessness among people with severe mental illness in Switzerland. Swiss Med Wkly 2005; 135(3-4):50-56.

23. Prince J, Akincigil A, Bromet E. Incarceration Rates of Persons With First-Admission Psychosis. Psychiatr Serv 2007; 58(9):1173-1180.

24. World Health Organization (WHO), Calouste Gulbenkian Foundation. Social determinants of mental health. Geneva: WHO; 2014.

25. Chen J, Chen J, Li S, Liu J, Ouyang, Luo W1, Guo X2, Li T, Li K, Li Z, Wang G. Comparisons of family environment between homeless and non-homeless individuals with schizophrenia in Xiangtan, Hunan. Shanghai Arch Psychiatry 2015; 27(3):175-182.

26. Kuno E, Rothbard A, Averyt J, Culhane D. Homelessness Among Persons With Serious Mental Illness in an Enhanced Community-Based Mental Health System. Psychiatr Serv 2000; 51(8):1012-1016.

27. Teplin LA, McClelland GM, Abram KM, Weiner DA. Crime Victimization in Adults With Severe Mental Illness: Comparison With the National Crime Victimization Survey. Arch Gen Psychiatry 2005; 62(8):911-921.

28. Massoglia M. Incarceration, Health, and Racial Disparities in Health. Law Soc Rev 2008; 42(2):275-306.

29. Primm AB, Vasquez MJT, Mays RA, Sammons-Posey D, McKnight-Eily LR, Presley-Cantrell LR, McGuire LC, Chapman DP, Perry GS. The Role of Public Health in Addressing Racial and Ethnic Disparities in Mental Health and Mental Illness. Prev Chronic Dis 2010; 7(1):A20
30. Quanbeck C, Stone D, McDermott B, Boone K, Scott C, Frye M. Relationship Between Criminal Arrest and Community Treatment History Among Patients With Bipolar Disorder. Psychiatr Serv 2005; 56(7):847-852.

31. Mattioni T, Di Lallo D, Roberti R, Miceli M, Stefani M, Maci C, Perucci C. Determinants of psychiatric inpatient admission to general hospital psychiatric wards: an epidemiological study in a region of central Italy. Soc Psychiatry Psychiatr Epidemiol 1999; 34(8):425-431.

32. Van Dorn R, Desmarais S, Petrila J, Haynes D, Singh J. Effects of Outpatient Treatment on Risk of Arrest of Adults With Serious Mental Illness and Associated Costs. Psychiatr Serv 2013; 64(9):856-862.

33. Constantine R, Robst J, Andel R, Teague G. The impact of mental health services on arrests of offenders with a serious mental illness. Law Hum Behav 2012; 36(3):170-176.

34. Jones TR, Pratt TC. The prevalence of sexual violence in prison: the state of the knowledge base and implications for evidence-based correctional policy making. Int J Offender Ther Comp Criminol 2008; 52(3):280295.

35. Toolis E, Hammack P. The lived experience of homeless youth: A narrative approach. Qualitative Psychology 2015; 2(1):50-68.

36. Tyler K. Social network characteristics and risky sexual and drug related behaviors among homeless young adults. Soc Sci Res 2008; 37(2):673-685.

Artigo apresentado em 25/05/2016

Aprovado em 21/10/2016

Versão final apresentada em 23/10/2016 
